\title{
Reduced lecithin:retinol acyltransferase expression in human breast cancer
}

\author{
MARNI SHEREN-MANOFF ${ }^{1}$, SANDRA J. SHIN $^{2}$, DAN SU ${ }^{3}$, DEAN BOK $^{4}$, \\ ROBERT R. RANDO ${ }^{5}$ and LORRAINE J. GUDAS ${ }^{3}$
}

\begin{abstract}
${ }^{1}$ Division of Hematology and Medical Oncology, Departments of ${ }^{2}$ Pathology and Laboratory Medicine and ${ }^{3}$ Pharmacology, New York Presbyterian Hospital-Weill Cornell Medical Center, 1300 York Avenue, New York, NY 10021;

${ }^{4}$ Department of Neurobiology and Brain Research Institute, Jules Stein Eye Institute, University of California at Los Angeles, 100 Stein Plaza, Los Angeles, CA 90095; ${ }^{5}$ Department of Biological Chemistry and Molecular Pharmacology, Harvard Medical School, 240 Longwood Avenue, Boston, MA 02115, USA
\end{abstract}

Received May 4, 2006; Accepted June 23, 2006

\begin{abstract}
Retinoids, vitamin A (retinol) and related metabolites, have been shown to be important in regulating cell growth and differentiation. We have shown that expression of the enzyme lecithin:retinol acyltransferase (LRAT), which converts retinol to retinyl esters, is reduced in several human carcinomas as compared with adjacent normal tissue from the same organs. The purpose of this research was to determine if aspects of retinoid signaling are impaired in human breast cancer. We evaluated LRAT protein expression in neoplastic and adjacent, non-neoplastic glandular breast tissue specimens from human patients. We evaluated 26 specimens from patients diagnosed with breast cancer between 2003 and 2005. Representative paraffin-embedded tissue blocks from each tumor, with each containing adjacent non-neoplastic glandular breast tissue, were examined by immunohistochemistry with affinity purified antibodies to human LRAT protein. LRAT protein was prominently detected throughout the non-neoplastic glandular breast tissue in all of the specimens. Areas of ductal carcinoma in situ and welldifferentiated invasive breast carcinomas showed an intensity of staining with the LRAT antibody which was similar to that
\end{abstract}

Correspondence to: Dr Lorraine J. Gudas, Weill Medical College of Cornell University, 1300 York Avenue, New York, NY 10021, USA

E-mail: ljgudas@med.cornell.edu

Abbreviations: ATRA, all-trans-retinoic acid; ARAT, acyl-CoA: retinol acyltransferase; DCIS, ductal carcinoma in situ; ER, estrogen receptor; LCIS, lobular carcinoma in situ; LRAT, lecithin:retinol acyltransferase; NMU, nitrosomethylurea; RA, retinoic acid; RAR, retinoic acid receptor; $\mathrm{RXR}$, retinoid $\mathrm{X}$ receptor

Key words: breast cancer, ductal carcinoma, lecithin:retinol acyltransferase, retinoid of the adjacent normal tissue. Expression of LRAT protein progressively decreased with a reduction in the degree of tumor differentiation in invasive breast carcinomas. LRAT protein levels correlate better with the degree of ductal tumor differentiation than does estrogen receptor status in this study. Furthermore, normal human breast epithelium exhibits intense LRAT staining, indicating a major role for LRAT in human breast physiology.

\section{Introduction}

In 2005, an estimated 212,930 women were diagnosed with breast cancer in the United States, and 40,870 died from the disease (1). Breast cancer is the most commonly occurring cancer among women, and is second only to lung cancer as a cause of cancer death in women (2). Breast cancer incidence in the United States has doubled over the past 60 years, from 55 per 100,000 in 1940 to 118 per 100,000 in 1998 (3). Thus, the identification of novel approaches for the prevention and treatment of breast cancer is urgently needed.

One class of agents that has been investigated for use in breast cancer treatment is the natural and synthetic analogs of vitamin A (retinol), a group of compounds known as retinoids. Retinoids have been shown to inhibit the proliferation and invasiveness of breast cancer cells (4-13). 9-Cis-retinoic acid prevented the development of ER-positive tumors in NMUtreated rats (14) and also suppressed the development of ER-negative mammary tumors in transgenic mice (15). In a phase II trial of 25 patients with advanced breast cancer who failed tamoxifen therapy, the addition of all-trans retinoic acid (ATRA) to continued tamoxifen led to one objective response and 6 patients had prolonged periods of stable disease (16).

The synthetic retinoid fenretinide (N-4-hydroxyphenyl retinamide, 4HPR) preferentially accumulates in the glandular and fat tissues of the mammary gland and has less systemic toxicity. It has been shown to inhibit MCF-7 cell growth (17) and to induce apoptosis even in ATRA-resistant cell lines (18). The combination of fenretinide and tamoxifen strongly inhibited the growth of ER-negative breast cancer cells in vitro, 
while either agent alone had only a minimal effect (19). In animal models, combined treatment with fenretinide and tamoxifen was more effective than either agent alone in preventing chemical-induced mammary tumors (20). In the Milan phase III fenretinide breast cancer prevention trial, it was found that fenretinide showed a trend towards a reduction in the incidence of second breast cancers in premenopausal women (21). Fenretinide is now being studied in combination with tamoxifen in breast cancer prevention trials (22). Fenretinide is also being assessed with and without tamoxifen in women with advanced breast cancer $(23,24)$.

Bexarotene (LG1069, Targretin), a synthetic retinoid X receptor-selective retinoid, prevented ER-positive NMUinduced rat mammary tumors (25) and also suppressed ER-negative mammary tumors in breast cancer mouse models (26). As with fenretinide, bexarotene plus tamoxifen has shown synergistic efficacy in preventing NMU-induced rat mammary tumors (8) and was also efficacious in rat mammary tumors after tamoxifen resistance or failure (27). Bexarotene has been well tolerated in phase I clinical trials, and is being examined in phase II clinical trials as a single agent and in combination with tamoxifen for advanced breast cancer (28).

The mechanisms by which retinoids regulate the growth and differentiation of cells and the role of retinoids in the pathogenesis of breast cancer have not been fully elucidated. The actions of retinoids are thought to be mediated by two different families of nuclear receptors, retinoic acid receptors (RAR) and retinoid X receptors (RXR); each family consists of receptor subtypes $\alpha, \beta, \gamma(29)$. When activated by their ligands, the retinoic acid receptors and the retinoid $\mathrm{X}$ receptors act as transcription factors and regulate the expression of retinoid responsive genes (30). Retinoic acid signaling is required for proper mammary gland development and for appropriate mammary gland differentiation (31). Conversely, the expression of the RARß2 gene has been found to be reduced in many malignant tumors, including invasive breast carcinoma $(6,9,32-34)$. These findings suggest that the loss of RARß2 expression may be an important event during tumorigenesis (35).

Retinol (vitamin A) can be metabolized into a variety of structurally related compounds. The esterification of retinol to retinyl esters is important for maintaining retinoids in a form that is easily stored and can be readily metabolized for the synthesis of retinoic acid $(36,37)$. This reaction is catalyzed by the enzyme lecithin:retinol acyltransferase (LRAT), which was previously cloned (38). LRAT protein expression has been shown to be regulated by exogenous retinoids (37). Our laboratory has previously shown that the metabolism of retinol to retinyl esters is greatly reduced in various human carcinoma cell lines, including prostate, kidney, skin, oral cavity and breast, as compared with normal human cultured epithelial cells from the same human tissues (39-43). Additionally, LRAT protein levels were shown to be reduced in tumor tissue from patients with renal, prostate and bladder carcinoma compared with adjacent normal tissue from these organs $(39,40,44,45)$. In bladder transitional cell carcinoma, LRAT mRNA and protein levels were found to decrease with an increase in pathological tumor stage (45). These data indicate that human carcinoma cells are retinoid deficient compared with normal epithelial cells, and that elevation or restoration of LRAT expression may be useful for carcinoma prevention and/or therapy.

LRAT expression has yet to be explored in human breast carcinoma. In this study, immunohistochemistry was used to evaluate the expression of LRAT protein in breast carcinoma pathological specimens in order to determine if levels of this protein are reduced in comparison with the levels found in normal breast epithelial tissue.

\section{Materials and methods}

Tissue specimens. Paraffin-embedded tissue specimens were obtained from the breast tumor tissue bank of the Department of Pathology at New York Presbyterian Hospital. Twenty-six cases of breast cancer diagnosed between 2003 and 2005 were included in this study. A representative tissue block from each tumor, with each containing adjacent non-neoplastic breast tissue, was selected for immunohistochemical analysis. The analysis of these tissues was approved by the Institutional Review Board of New York Presbyterian Hospital. All patient identifiers were removed prior to our acquisition of these specimens.

Immunohistochemistry. Tissue localization of LRAT protein was performed using an affinity-purified, polyclonal rabbit anti-human LRAT antibody (38). Tissue sections (4- $\mu \mathrm{m})$ were cut from paraffin blocks in the Pathology Department of New York Presbyterian Hospital. Immunostaining was performed following antigen retrieval on the automated Techmate $500^{\mathrm{TM}}$ immunostainer (Ventana Medical Systems, Tucson, AZ). Affinity-purified, anti-human LRAT primary anti-serum, generated in rabbits, was used at a 1:300 dilution in $4 \%$ normal human serum. The negative control sections were treated identically to all other sections except that $4 \%$ normal human serum was used in place of the primary antibody. All samples were analyzed using this exact protocol.

Grading of LRAT immunoreactivity. The expression of LRAT protein was scored in a semiquantitative fashion by a single pathologist (Dr Sandra J. Shin). Because each tumor showed diffuse immunoreactivity for LRAT, the number of positive staining cells could not be used for grading the staining. Specimens were evaluated for intensity of staining within areas of tumor compared with the intensity of staining in adjacent areas of non-neoplastic breast tissue. Intensity of staining was graded as 0 (no staining), 1+ (weak but just detectable staining), 2+ (distinct staining, weaker than the staining in non-neoplastic breast tissue), and 3+ (staining equal to or more intense than that in non-neoplastic tissue). The immunohistochemistry procedure and histopathologic evaluation were performed independently and the researchers were blinded to pathological tumor stage.

\section{Results}

LRAT protein staining in normal breast tissue. The expression of LRAT protein in normal human breast tissue has not been examined previously. We found that the normal, non-neoplastic human breast tissue exhibited a high level of diffuse, cytoplasmic staining in the epithelial cells of the mammary glands 
Table I. Patient and tumor characteristics.

\begin{tabular}{|c|c|c|c|}
\hline \multicolumn{4}{|l|}{ Age at diagnosis (year) } \\
\hline Mean & \multicolumn{3}{|l|}{62} \\
\hline Range & \multicolumn{3}{|l|}{$41-90$} \\
\hline \multicolumn{4}{|l|}{ Tumor size $(\mathrm{cm})$} \\
\hline$>2$ & \multicolumn{3}{|l|}{11} \\
\hline$<2$ & \multicolumn{3}{|l|}{15} \\
\hline \multicolumn{4}{|l|}{ Node status (no. of cases) } \\
\hline Positive & \multicolumn{3}{|l|}{8} \\
\hline Negative & \multicolumn{3}{|l|}{18} \\
\hline \multicolumn{4}{|c|}{ Carcinoma subtype (no. of cases) } \\
\hline Ductal & \multicolumn{3}{|l|}{19} \\
\hline Lobular & \multicolumn{3}{|l|}{3} \\
\hline Mucinous & \multicolumn{3}{|l|}{3} \\
\hline Metaplastic & \multicolumn{3}{|l|}{1} \\
\hline \multicolumn{4}{|l|}{$\begin{array}{l}\text { Degree of differentiation (for } \\
\text { ductal carcinoma cases) }\end{array}$} \\
\hline Well & \multicolumn{3}{|l|}{4} \\
\hline Moderate & \multicolumn{3}{|l|}{8} \\
\hline Poor & \multicolumn{3}{|l|}{7} \\
\hline $\begin{array}{l}\text { Hormone receptor status (for } \\
\text { ductal cases, according to } \\
\text { degree of differentiation) }\end{array}$ & \multicolumn{3}{|c|}{$\begin{array}{l}\text { (no. of positive cases/ } \\
\text { total no. of cases) }\end{array}$} \\
\hline Well & $4 / 4$ & $4 / 4$ & $0 / 4$ \\
\hline Moderate & $6 / 8$ & $6 / 8$ & $1 / 8$ \\
\hline Poor & $7 / 7$ & $5 / 7$ & $0 / 7$ \\
\hline
\end{tabular}

(Fig. 1a). In each case, the intensity of staining in normal mammary glands was used as a baseline from which to grade the staining of the adjacent tumor cells. None of the negative controls showed staining either in the tumor or in the nonneoplastic adjacent breast tissue (Fig. 1b).

Patient demographics and subtypes of breast neoplasms. Among the 26 tumors, there were 19 cases of ductal carcinoma, three lobular carcinoma, three mucinous carcinoma, and one metaplastic carcinoma case. Among the 19 ductal carcinoma cases, four were well-differentiated tumors, eight were moderately differentiated tumors, and seven were poorly differentiated tumors. The patient ages at diagnosis ranged from 41 to 90 , with a mean of 62 (Table I).

LRAT expression in human breast tumor tissues. In each case, staining was generally uniform throughout the tumor, with only a few exceptions of staining variability. Among the 19 cases of invasive ductal carcinoma, all adjacent foci of DCIS (ductal carcinoma in situ) showed 2-3+ immunostaining, similar to the immunostaining of the adjacent normal glandular breast tissue in each case (Fig. 2). The well-differentiated invasive ductal carcinomas, characterized by a high degree of glandular differentiation, minimal nuclear atypia and a low number of mitotic figures, all showed 2-3+ immunostaining, similar to that of the $3+$ staining seen in normal glandular breast tissue (Fig. 3). The moderately differentiated invasive ductal carcinomas showed a range of 1-3+ immunostaining, but were most often graded as $2+$ (Fig. 4). The poorly differentiated invasive ductal carcinomas, characterized by little to no glandular formation, marked nuclear atypia, and frequent mitotic figures, showed a range of $0-2+$ immunostaining (Fig. 5). Although this study involved a relatively small number of patients, the LRAT expression levels correlated better with the degree of ductal tumor differentiation than did estrogen receptor (ER) status (Table I).

Less common subtypes of invasive breast cancers, such as lobular carcinoma and mucinous carcinoma, exhibited a higher degree of immunostaining with the LRAT antibody. Lobular carcinoma stained in the 2-3+ range, and mucinous carcinoma stained 3+ with LRAT, closer to the degree of immunostaining seen in non-neoplastic breast tissue (Figs. 6 and 7).

\section{Discussion}

Retinyl esters are the predominant metabolites of retinol (vitamin A) in most epithelial cells and tissues, and the esterification of retinol is believed to be involved in its cellular uptake and storage. Retinyl esters may also serve as an internal source of retinol for the synthesis of retinoic acid. Retinoic acid is a ligand for the nuclear retinoic acid receptors, which then bind to retinoic acid response elements in target genes and regulate gene transcription (46-49). Two enzymes have been reported to catalyze retinyl ester synthesis, LRAT and acyl-CoA: retinol acyltransferase (ARAT). Our lab has shown that LRAT levels are low in many carcinoma cell lines and human tumor specimens relative to normal human epithelial tissue (39-43). Reduced expression of LRAT could result in reduced levels of intracellular retinoids, and affected cells would then be functionally retinoid deficient.

Support for the idea that the loss of or abnormalities in retinoid biosynthesis contributes to tumor formation comes from other recent studies as well. Several different enzyme abnormalities in retinol metabolism have been identified in tumor specimens and cell lines from various types of cancer. More specifically, both in human breast carcinoma cell lines (41) and in NMU-induced mammary carcinomas in rats (50), greatly reduced levels of endogenous retinol or retinyl esters could be detected and there was an absence of retinyl ester formation from injected $\left[{ }^{3} \mathrm{H}\right]$ retinol. In contrast, active metabolism of retinol to retinyl esters occurred in intestine, kidney, and normal mammary glands (50). Retinoic acid uptake and metabolism were shown to be as active in breast tumors as in the other tissues examined, suggesting that a specific abnormality in the uptake or esterification of retinol was present in the NMU-induced breast tumors (50). No alterations in the activity of either ARAT or retinyl ester hydrolase were seen in the rat mammary tumors compared to the normal mammary gland, but a significant decrease in retinal oxidase activity was seen in the tumor tissue compared to normal tissue (50).

Other retinoid metabolic enzyme abnormalities have been found in several types of cancers. Expression of RetSDR1, a 


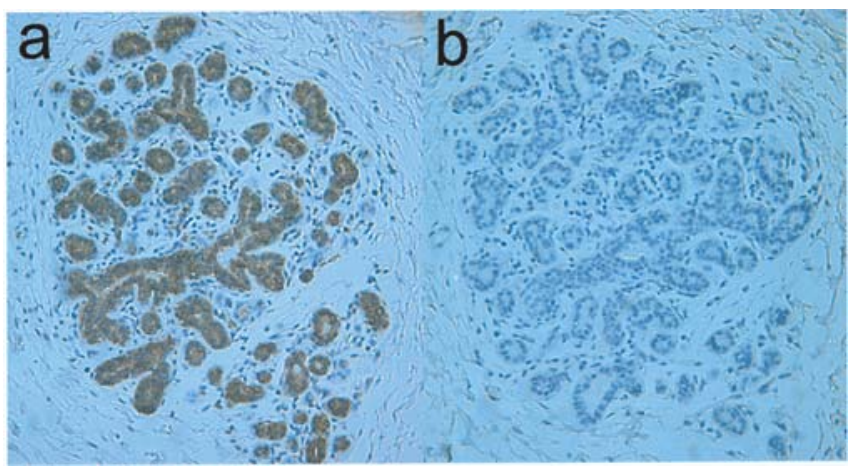

Figure 1. Immunohistochemistry of lecithin:retinol acyltransferase (LRAT) protein in paraffin-embedded sections of normal and neoplastic breast tissue. (a) Normal terminal duct lobular unit showing diffuse 3+ LRAT protein expression, indicated by the brown stain. (b) Absence of immunostaining in the negative control specimen (LRAT immunohistochemical stain; magnification $\times 200$ ).

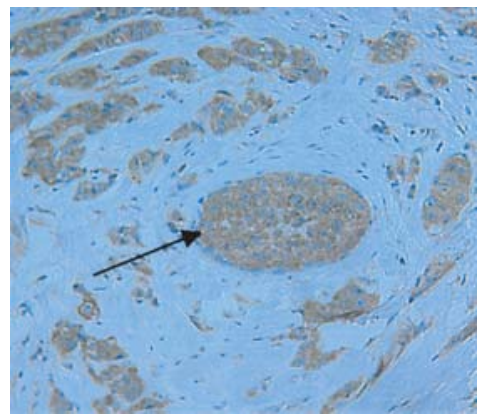

Figure 2. Ductal carcinoma in situ (DCIS, arrow), amid surrounding invasive ductal carcinoma, with 2-3+ staining intensity similar to the staining intensity of normal glandular breast tissue (LRAT immunohistochemical stain; magnification $\times 200$ ).

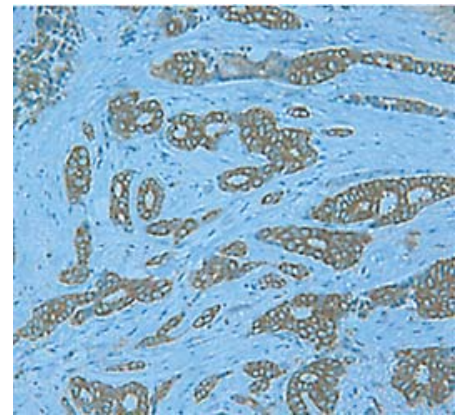

Figure 3.3+ staining intensity (equivalent intensity to the normal glandular breast tissue) with LRAT antibody in a well-differentiated, invasive ductal carcinoma with a high degree of glandular formation, minimal nuclear atypia and rare mitotic figures (LRAT immunohistochemical stain; magnification $\mathrm{x} 200)$.

gene involved in retinol storage, was found to be greatly reduced or lost in some neuroblastomas (51). Reduced expression of the retinoid biosynthesis genes retinol dehydrogenase 5 (RDH5) and retinol dehydrogenase L (RDHL) was found in colon adenomas and carcinomas as compared with normal colon. Seven human colon carcinoma cell lines also lacked expression of RDH5 and RDHL; assessment of RDH enzyme activity showed decreased conversion of retinol to retinaldehyde

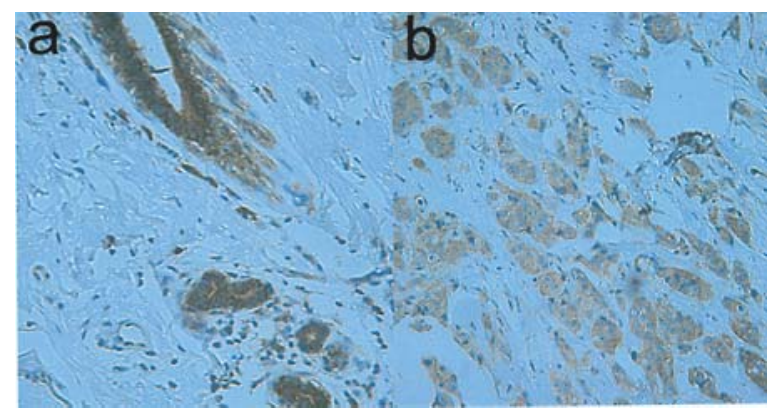

Figure 4. (a) Normal breast glands with $3+$ staining intensity with LRAT antibody. (b) 2+ staining intensity with LRAT antibody in a moderately differentiated, invasive ductal carcinoma from the same patient (LRAT immunohistochemical stain; magnification x200).

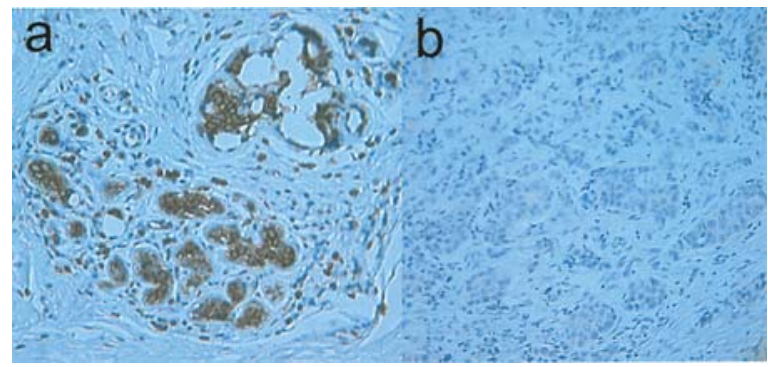

Figure 5. (a) Normal breast glands with $3+$ staining intensity with LRAT antibody. (b) 0-1+ staining intensity with LRAT antibody in a poorly differentiated, invasive ductal carcinoma from the same patient; the tumor exhibits little to no glandular formation, marked nuclear atypia and frequent mitotic figures (LRAT immunohistochemical stain; magnification x200).



Figure 6. (a) Normal breast gland with $3+$ staining intensity with LRAT antibody. (b) Mucinous carcinoma from the same patient: clusters of tumor cells in pools of mucin exhibit $2-3+$ staining intensity with the LRAT antibody (LRAT immunohistochemical stain; magnification x200).

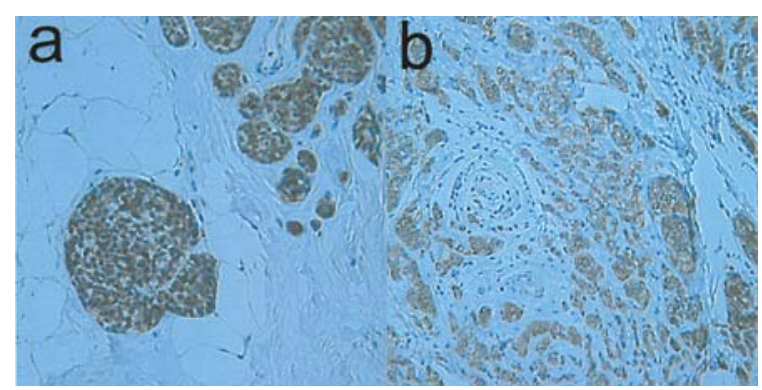

Figure 7. (a) Lobular carcinoma in situ (LCIS) with 3+ staining intensity, similar to staining intensity of normal breast glands. (b) Invasive lobular carcinoma from the same patient, with 2-3+ staining intensity with LRAT antibody (LRAT immunohistochemical stain; magnification x200). 


\section{LRAT Staining Intensity of Tumor Subtypes}

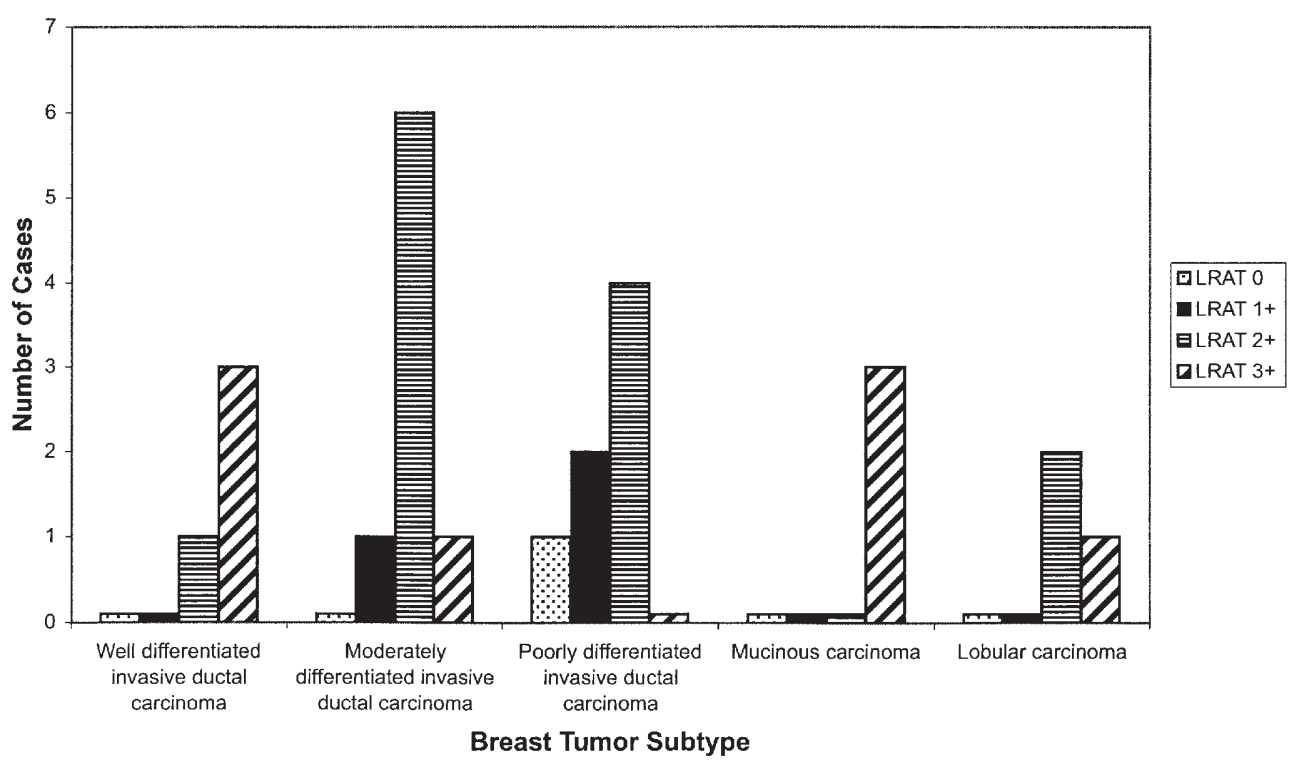

Figure 8. Quantitation of LRAT staining intensity of tumor subtypes.

and subsequently to retinoic acid in tumor lines as compared with normal epithelial cells, such as normal human epithelial cells (52). Certain human breast cancer cell lines do not synthesize retinoic acid from retinol, and reintroduction of RALDH6, a retinaldehyde dehydrogenase, restored the ability of MCF-7 breast cancer cells to synthesize retinoic acid $(53,54)$. Expression of the gene for aldehyde dehydrogenase 1 family, member A2 (ALDH1a2), which catalyzes the oxidation of retinaldehyde to retinoic acid, was shown to be reduced in human prostate tumors compared with normal prostate (55). Reduced expression of ALDH1a2 (RALDH6) was also associated with a shorter recurrence-free survival in prostate cancer patients (55). ALDH1a2 was expressed in normal prostate but not in the cancerous epithelium. The ALDH1a2 promoter was shown to be hypermethylated in prostate tumors, consistent with methylation-mediated gene silencing. Moreover, reexpression of wild-type ALDH1a2 in human prostate cancer cells inhibited cell growth, consistent with a tumor suppressor function (55). All of the aforementioned data suggest that defects in retinoid metabolism, leading to a deficiency in the bioactive retinoid all-trans retinoic acid, are common features of cancer cells.

We used immunohistochemistry to investigate the expression of LRAT protein in human breast carcinoma specimens. We found that LRAT expression was more intense in the non-neoplastic glandular breast tissue as compared to its expression in adjacent invasive breast carcinoma, and LRAT expression decreased with a reduction in degree of tumor differentiation (Fig. 8). Less common subtypes of invasive cancers, lobular carcinoma and mucinous carcinoma, exhibited a greater amount of immunostaining with the LRAT antibody, similar to that seen in the non-neoplastic glandular breast tissue. These data extend our previous research and suggest that a reduction in LRAT expression may be a general characteristic of progressive carcinogenesis. However, the mechanism(s) through which LRAT expression is altered in cancer cells are not yet understood. Our study involved the use of paraffinembedded specimens and we were not able to obtain mRNA from these patient samples. Thus, it was not possible to determine whether the lower LRAT protein expression in the areas of tumor compared to non-neoplastic breast tissue resulted from promoter methylation versus instability of mRNA and/or protein. The use of frozen specimens from these patients was considered, but it was felt that the time interval between tissue acquisition and freezing was too long to obtain sufficient amounts of undegraded mRNA. In the future, it would be worthwhile to perform RT-PCR and Western blotting on fresh breast tumor and normal tissue.

Specimens analyzed in our study were obtained from patients diagnosed with breast cancer within the past three years and their long-term outcomes are not known. The question of whether LRAT expression level has any prognostic value cannot be answered in a study of this size and would require the assessment of a greater number of cases with much longer clinical follow-up.

Retinoid-induced mRNA expression of several retinoidresponsive genes has been shown previously in human bladder cancer cell lines (56). Given the importance of retinoids in cell growth and differentiation (30) and the role of LRAT in maintaining retinoid levels in tissues $(39,40)$, increasing LRAT expression and/or providing pharmacological doses of retinoids to the tumor may be useful as potential strategies for cancer prevention and therapy. Whether restoration or elevation of LRAT expression alone would enable normal retinoid signaling is not yet clear. In our study, most tumor specimens showed a decrease, but not absence, of LRAT protein expression; this suggests that other mechanisms are also involved in progression to carcinogenesis. Further research is needed to elucidate this, as well as the molecular mechanism(s) by which LRAT expression is altered in cancer cells. Measurement of retinol levels in both normal and neoplastic human breast tissue would also be of value. 


\section{Acknowledgements}

We thank Dr Satish Tickoo for advice on the staining procedure. We also thank the members of the Gudas laboratory, especially Sue Ellen Touma, and Karl Ecklund for editorial efforts. This research was supported by the NIH R01 DE10389 and NIH R01 CA097543 grants to Lorraine J. Gudas, and R01 EY00444 and R01 EY00331 to Dean Bok.

\section{References}

1. Jemal A, Murray T, Ward E, et al: Cancer statistics, 2005. CA Cancer J Clin 55: 10-30, 2005.

2. Stewart SL, King JB, Thompson TD, Friedman C and Wingo PA: Cancer mortality surveillance - United States, 1990-2000. MMWR Surveill Summ 53: 1-108, 2004.

3. Ries LA: SEER Cancer Statistics Review 1975-2001, 2004

4. Yang L, Kim HT, Munoz-Medellin D, Reddy P and Brown PH: Induction of retinoid resistance in breast cancer cells by overexpression of cJun. Cancer Res 57: 4652-4661, 1997.

5. Rubin M, Fenig E, Rosenauer A, et al: 9-Cis retinoic acid inhibits growth of breast cancer cells and down-regulates estrogen receptor RNA and protein. Cancer Res 54: 6549-6556, 1994.

6. Van der Burg B, van der Leede BM, Kwakkenbos-Isbrucker L, Salverda S, De Laat SW and van der Saag PT: Retinoic acid resistance of estradiol-independent breast cancer cells coincides with diminished retinoic acid receptor function. Mol Cell Endocrinol 91: 149-157, 1993.

7. Wu Q, Dawson MI, Zheng Y, et al: Inhibition of trans-retinoic acid-resistant human breast cancer cell growth by retinoid $\mathrm{X}$ receptor-selective retinoids. Mol Cell Biol 17: 6598-6608, 1997.

8. Bischoff ED, Gottardis MM, Moon TE, Heyman RA and Lamph WW: Beyond tamoxifen: the retinoid X receptor-selective ligand LGD1069 (TARGRETIN) causes complete regression of mammary carcinoma. Cancer Res 58: 479-484, 1998.

9. Li XS, Shao ZM, Sheikh MS, et al: Retinoic acid nuclear receptor beta inhibits breast carcinoma anchorage independent growth. J Cell Physiol 165: 449-458, 1995.

10. Dawson MI, Chao WR, Pine P, et al: Correlation of retinoid binding affinity to retinoic acid receptor alpha with retinoid inhibition of growth of estrogen receptor-positive MCF-7 mammary carcinoma cells. Cancer Res 55: 4446-4451, 1995.

11. Teixeira $\mathrm{C}$ and Pratt MA: CDK2 is a target for retinoic acidmediated growth inhibition in MCF-7 human breast cancer cells. Mol Endocrinol 11: 1191-1202, 1997.

12. Zhou Q, Stetler-Stevenson M and Steeg PS: Inhibition of cyclin D expression in human breast carcinoma cells by retinoids in vitro. Oncogene 15: 107-115, 1997.

13. Widschwendter M, Daxenbichler G, Culig Z, et al: Activity of retinoic acid receptor-gamma selectively binding retinoids alone and in combination with interferon-gamma in breast cancer cell lines. Int J Cancer 71: 497-504, 1997.

14. Anzano MA, Byers SW, Smith JM, et al: Prevention of breast cancer in the rat with 9-cis-retinoic acid as a single agent and in combination with tamoxifen. Cancer Res 54: 4614-4617, 1994.

15. Wu K, Kim HT, Rodriquez JL, et al: 9-cis-retinoic acid suppresses mammary tumorigenesis in C3(1)-simian virus $40 \mathrm{~T}$ antigentransgenic mice. Clin Cancer Res 6: 3696-3704, 2000.

16. Budd GT, Adamson PC, Gupta M, et al: Phase I/II trial of alltrans retinoic acid and tamoxifen in patients with advanced breast cancer. Clin Cancer Res 4: 635-642, 1998.

17. Fontana JA: Interaction of retinoids and tamoxifen on the inhibition of human mammary carcinoma cell proliferation. Exp Cell Biol 55: 136-144, 1987.

18. Ulukaya E and Wood EJ: Fenretinide and its relation to cancer. Cancer Treat Rev 25: 229-235, 1999.

19. Aoyama Y: Experimental studies on the effects of the combined use of N-(4-hydroxyphenyl)retinamide (4-HPR) and tamoxifen (TAM) for estrogen receptor (ER)-negative breast cancer. Kurume Med J 49: 27-33, 2002.

20. Moon RC, Kelloff GJ, Detrisac CJ, Steele VE, Thomas CF and Sigman CC: Chemoprevention of MNU-induced mammary tumors in the mature rat by $4-H P R$ and tamoxifen. Anticancer Res 12: 1147-1153, 1992.

21. Decensi A, Serrano D, Bonanni B, Cazzaniga M and GuerrieriGonzaga A: Breast cancer prevention trials using retinoids. J Mammary Gland Biol Neoplasia 8: 19-30, 2003.
22. Singletary SE, Atkinson EN, Hoque A, et al: Phase II clinical trial of N-(4-Hydroxyphenyl)retinamide and tamoxifen administration before definitive surgery for breast neoplasia. Clin Cancer Res 8: 2835-2842, 2002.

23. Modiano MR, Dalton WS, Lippman SM, Joffe L, Booth AR and Meyskens FL Jr: Phase II study of fenretinide [N-(4hydroxyphenyl)retinamide] in advanced breast cancer and melanoma. Invest New Drugs 8: 317-319, 1990.

24. Cobleigh MA, Dowlatshahi K, Deutsch TA, et al: Phase I/II trial of tamoxifen with or without fenretinide, an analog of vitamin A, in women with metastatic breast cancer. J Clin Oncol 11: 474-477, 1993

25. Gottardis MM, Bischoff ED, Shirley MA, Wagoner MA, Lamph WW and Heyman RA: Chemoprevention of mammary carcinoma by LGD1069 (Targretin): an RXR-selective ligand. Cancer Res 56: 5566-5570, 1996.

26. Wu K, Zhang Y, Xu XC, et al: The retinoid X receptor-selective retinoid, LGD1069, prevents the development of estrogen receptor-negative mammary tumors in transgenic mice. Cancer Res 62: 6376-6380, 2002

27. Bischoff ED, Heyman RA and Lamph WW: Effect of the retinoid X receptor-selective ligand LGD1069 on mammary carcinoma after tamoxifen failure. J Natl Cancer Inst 91: 2118, 1999.

28. Esteva FJ, Glaspy J, Baidas S, et al: Multicenter phase II study of oral bexarotene for patients with metastatic breast cancer. J Clin Oncol 21: 999-1006, 2003.

29. Mangelsdorf D, Umesono K and Evans RM: The retinoid receptors. In: The Retinoids: Biology, Chemistry and Medicine. 2nd edition, Sporn MB, Roberts AB and Goodman DS (eds). Raven Press, New York, pp319-350, 1994.

30. Gudas LJ, Sporn MB and Roberts AB: Cellular biology and biochemistry of the retinoids. In: The Retinoids: Biology, Chemistry and Medicine. 2nd edition, Sporn MB, Roberts AB and Goodman DS (eds). Raven Press, New York, pp443-518, 1994.

31. Wang YA, Shen K, Wang Y and Brooks SC: Retinoic acid signaling is required for proper morphogenesis of mammary gland. Dev Dyn 234: 892-899, 2005.

32. Widschwendter M, Berger J, Daxenbichler G, et al: Loss of retinoic acid receptor beta expression in breast cancer and morphologically normal adjacent tissue but not in the normal breast tissue distant from the cancer. Cancer Res 57: 4158-4161, 1997.

33. Xu XC, Sneige N, Liu X, et al: Progressive decrease in nuclear retinoic acid receptor beta messenger RNA level during breast carcinogenesis. Cancer Res 57: 4992-4996, 1997.

34. Sirchia SM, Ferguson AT, Sironi E, Subramanyan S, Orlandi R, Sukumar S and Sacchi N: Evidence of epigenetic changes affecting the chromatin state of the retinoic acid receptor beta2 promoter in breast cancer cells. Oncogene 19: 1556-1563, 2000.

35. Yang Q, Sakurai T and Kakudo K: Retinoid, retinoic acid receptor beta and breast cancer. Breast Cancer Res Treat 76: $167-173,2002$.

36. Blomhoff R, Green MH, Berg T and Norum KR: Transport and storage of vitamin A. Science 250: 399-404, 1990.

37. Ross AC: Retinoid production and catabolism: role of diet in regulating retinol esterification and retinoic Acid oxidation. $\mathbf{J}$ Nutr 133: S291-S296, 2003.

38. Ruiz A, Winston A, Lim YH, Gilbert BA, Rando RR and Bok D: Molecular and biochemical characterization of lecithin retinol acyltransferase. J Biol Chem 274: 3834-3841, 1999.

39. Guo X, Knudsen BS, Peehl DM, et al: Retinol metabolism and lecithin:retinol acyltransferase levels are reduced in cultured human prostate cancer cells and tissue specimens. Cancer Res 62: 1654-1661, 2002.

40. Guo X, Nanus DM, Ruiz A, Rando RR, Bok D and Gudas LJ: Reduced levels of retinyl esters and vitamin $\mathrm{A}$ in human renal cancers. Cancer Res 61: 2774-2781, 2001

41. Chen AC, Guo X, Derguini F and Gudas LJ: Human breast cancer cells and normal mammary epithelial cells: retinol metabolism and growth inhibition by the retinol metabolite 4oxoretinol. Cancer Res 57: 4642-4651, 1997.

42. Guo X and Gudas LJ: Metabolism of all-trans-retinol in normal human cell strains and squamous cell carcinoma (SCC) lines from the oral cavity and skin: reduced esterification of retinol in SCC lines. Cancer Res 58: 166-176, 1998.

43. Guo X, Ruiz A, Rando RR, Bok D and Gudas LJ: Esterification of all-trans-retinol in normal human epithelial cell strains and carcinoma lines from oral cavity, skin and breast: reduced expression of lecithin:retinol acyltransferase in carcinoma lines. Carcinogenesis 21: 1925-1933, 2000. 
44. Zhan HC, Gudas LJ, Bok D, Rando R, Nanus DM and Tickoo SK: Differential expression of the enzyme that esterifies retinol, lecithin:retinol acyltransferase, in subtypes of human renal cancer and normal kidney. Clin Cancer Res 9: 4897-4905, 2003.

45. Boorjian S, Tickoo SK, Mongan NP, et al: Reduced lecithin: retinol acyltransferase expression correlates with increased pathologic tumor stage in bladder cancer. Clin Cancer Res 10: 3429-3437, 2004

46. Pemrick SM, Lucas DA and Grippo JF: The retinoid receptors Leukemia 8: 1797-1806, 1994.

47. Aranda A and Pascual A: Nuclear hormone receptors and gene expression. Physiol Rev 81: 1269-1304, 2001.

48. Nagpal S and Chandraratna RA: Recent developments in receptor-selective retinoids. Curr Pharm Des 6: 919-931, 2000

49. Lee KC and Lee Kraus W: Nuclear receptors, coactivators and chromatin: new approaches, new insights. Trends Endocrinol Metab 12: 191-197, 2001.

50. Bhat PV and Lacroix A: Metabolism of retinol and retinoic acid in N-methyl-N-nitrosourea-induced mammary carcinomas in rats. Cancer Res 49: 139-144, 1989.

51. Cerignoli F, Guo X, Cardinali B, et al: retSDR1, a short-chain retinol dehydrogenase/reductase, is retinoic acid-inducible and frequently deleted in human neuroblastoma cell lines. Cancer Res 62: 1196-1204, 2002.
52. Jette C, Peterson PW, Sandoval IT, Manos EJ, Hadley E, Ireland CM and Jones DA: The tumor suppressor adenomatous polyposis coli and caudal related homeodomain protein regulate expression of retinol dehydrogenase L. J Biol Chem 279: 34397-34405, 2004

53. Mira YLR, Zheng WL, Kuppumbatti YS, Rexer B, Jing Y and Ong DE: Retinol conversion to retinoic acid is impaired in breast cancer cell lines relative to normal cells. J Cell Physiol 185: 302-309, 2000

54. Rexer BN, Zheng WL and Ong DE: Retinoic acid biosynthesis by normal human breast epithelium is via aldehyde dehydrogenase 6, absent in MCF-7 cells. Cancer Res 61: 7065-7070, 2001.

55. Kim H, Lapointe J, Kaygusuz G, et al: The retinoic acid synthesis gene ALDH1a2 is a candidate tumor suppressor in prostate cancer. Cancer Res 65: 8118-8124, 2005.

56. Waliszewski P, Waliszewska M, Gordon N, Hurst RE, Benbrook DM, Dhar A and Hemstreet GP III: Retinoid signaling in immortalized and carcinoma-derived human uroepithelial cells. Mol Cell Endocrinol 148: 55-65, 1999. 